\title{
The Effectiveness Of Folk Dance Expression Program On Some Physiological Variables And Cortisol Hormone To Relieve Psychological Stress In Refugee Women
}

\author{
Prof. Eman Mahmoud El-Sherief \\ Dr. Sherin Mohamed Ali
}

\section{Introduction}

Health is a human condition with physical, social and psychological dimensions. Each dimension continuously affects negatively and positively so that the individual can enjoy life and face challenges. Psychological pressures have become one of the most prevalent mental disorders. This made us call this era an era of psychological stress.

Psychological stress is considered a danger to the health of the individual and his psychological balance and its consequence negative effects such as the inability to adapt, the decrease of level of performance, and the inability to perform the tasks of daily life. (19: 281: 322)

The word stress refers to the limit that leads to tension or excitation, and these stresses appear when the individual is exposed to continuous environmental difficulties. The individual tries to overcome these difficulties by means of adapting to environmental conditions to maintain the state of stability. (16:23).

Stress is a painful or unpleasant emotional state that the individual tries to avoid and negatively affects the performance through eexcessive muscle tension. (30: 302). Stress is defined by Wafaa Darwish (2014) as the degree to which individuals respond to events or environmental changes in their daily life and these change may be painful to the extent that physiological effects may occur even though these effects differ from one person to another depending on the composition of his personality and psychological characteristics. (43: 213).

Abd El-Aziz Fahmy (2001) indicated that psychological stress has different forms, some are related to the health status of the individual, family, accommodation, school, and work, economic and environment conditions surrounding the individual, crises and disasters, and the surrounding social environment. (1: 143)

Lazarous and Cohen (1991) indicated that there are two types of stresses: external environmental stress which includes events that occur in the environment, and internal environmental stress which includes those changes that occur within the individual as an indication of his trend towards the outside world (22:61)

Cooper and Marshall (1979) also pointed out that there are seven sources of external stress including work stress, environment and climate, stress of internal relations in environmental organizations, stress from global organizations. There is only one source of internal stress that come from personal components for the individual. (9: 119)

Many Arab and foreign studies have focused on treating psychological stress by using many different programs. The study of Nabila Abu Habib (2010) (33) aimed at identifying psychological stress and strategies to confront them and their relationship to academic achievement among the children of the martyrs in the governorates of Gaza. The study of Heba Gharib (2010) (17) aimed at the effectiveness of a guidance program based on sports activities to relieve psychological stress. The study of Khaled Al-Hashemi (2011) (20) aimed to identify the effectiveness of a guidance program to reduce psychological stress among high school students in Kuwait. The study of Amani Mahmoud (2018) (5) aimed to find the effect of a sports program on the level of the serotonin hormone to reduce psychological stress and to improve the quality of life for women. The study of Maryam Hanna (2018) (26) aimed to 
identify the psychological stress and its relationship to the patterns of the gene (SLC6A4) for some players of high levels of sports. The study of Nawal Abd Al-Rahman (2018) (35) aimed to find the effectiveness of a training program as a treatment to overcome stress and alleviating anxiety and depression among a sample of high school students in the Kingdom of Bahrain.

Evidences indicate the importance of physical activity for human physical and psychological health, and there is no doubt that the human body is positively affected by physical exercise in various stages of life. Practicing aerobic physical activity is one of the best types of activities because it affects the heart, lungs and the body in general because many physiological changes occur that lead to the effectiveness of all vital systems and the nervous system. The endocrine system also responds to physical activities and this emphasizes the important role of the hormonal system and adaptation process in the response physical activity $(7: 417,419,427,428)$.

Berenbaum H. and Fujita F. (1994), Kopp B. et al. (1994), Mohamad Al-Hamami (1997), Helmy Ibraheem and Laila El-Sayed (1998) agree that sport is one of the contemporary social phenomenon that is concerned with the physical health of the individual and his way of life to defend himself against the changes of society and to protect himself from many modern diseases related to mental illnesses with the aim of achieving a better life for the individual and getting a positive effect on the individual's health, physical, educational, psychological, and social aspects. (8:48), (21: 129), (31: 25-26), (18: 5- 52)

Folk dance is considered one of the oldest types of dance for its close relation to history and civilization and it expresses the national spirit and national features of each society. It is a way to translate feelings, beliefs and natures of peoples and it plays an important role in recreation of oneself. All civilized societies involve folk dance in their celebrations and parties, and for this, folk dance is a social phenomenon and a factor that influences the psyche of peoples. (3: 14-15)

Fatma El-Azab (1990), Iglal Ibrahim and Nadia Darwish (1994), and Nabil Ragheb (1998) agreed on the definition of folk dance that it is "expressive steps and movements emanating from the environment expressing society customs and traditions in a distinctive character ". Finally we can define folk dance as " a type of folk art that sincerely expresses the feelings of peoples and tells their history and preserves its heritage as its steps and music are passed on to generations and is attractive for all people "(13: 6, 19), (10:49), (34: 27).

The importance of folk dance varies to include many aspects such as: physical importance as folk dance is a physical activity that affects in building and shaping the body, gaining good strength, increasing the efficiency of the body systems, and contributing in raising the level of physical fitness and beauty in performance; social importance as folk dance are easy, spontaneous, and group movements which encourages individuals of both sexes and from all levels of society to practice it and provide friendship and familiarity ties between individuals. In the same time it helps the individual to release his emotions and form his personality, mental, and psychological health; national importance as folk dance is a way to develop international understanding and respect for other cultures between nations and it is one of the means to revive studies of Folklore and the arts; and finally the entertainment importance as folk dance brings happiness and fun that the individual gains from dancing in a group characterized by friendliness and respect for others and relieving from mental exhaustion and emotional anxiety. (13: $5,13-16,27)$ 
Each nation is distinguished by its different dances that adheres to the manifestations of the social environment and the inherited traditions in this nation and is part of the heritage of peoples and is a sign of the renaissance and civilization of this nation. (13: 105). There are many names for folk dance such as the national dance and Dabke dances. In the past, dancing in the Levant countries was ancient ceremonies related to the environment such as collecting agricultural crops in Syria, Lebanon and Iraq and these ceremonies are filled with joy during which sell, purchase, marriage, dances, and singing are commonly practiced. There are other festivals in Syria, such as the Vine, Apple and Cotton Festival, all of which are events that reflect the expression of joy. The folklore reveals to us the extent of common participation between the Levant countries in these festivals. Example of common dances is the Dabke dance which is considered the most common dance that are prevalent in the Levant countries. Dabke dance is a group dance performed by men and women together where they line up in the form of a monolithic ring, each person holds the hand of his companion in an indication of common life and cooperative spirit within the group. The dance group has a leader called (Loeeh) who instructs the participants to maintain the rhythm and the good performance.There are many types of Dabke dance such as: Shamala, Ghazala, Bedouin, Shaarawiya, Golaniya, Farawiya and Palestinian Dabke among others. (12: 41-43)

Some Arab studies were conducted in the motor expression and its effect on health aspects. The study of El-Sayed Derbala (1999) (11) aimed to find the effect of show exercises in some physiological variables reduction of body circumferences, fat and body weight. The study Alia Shams El-Din (2004) (4) aimed at finding the effect of Tae Bo exercises to improve some physical variables and physiological variables and body composition variables on the level of performance in modern dance.

\section{Research problem and its importance}

The current research problem lies in the fact that while one of the researchers was working in the fitness center of the London Islamic Mosque in Canada, where the mosque has a center to help refugees and follow up on their lives, and with the arrival of a group of refugee women to Canada and studying their condition, the researcher found that they suffer from a set of health problems and stress that negatively affects their lives and their feeling of alienation. The researchers reviewed scientific references and previous studies and found that there are less studies that dealt with problems affecting refugee women. This called for researchers to design a folk dance Expression program and identify its impact on the level of the hormone cortisol and some morphological and physiological variables to relief the psychological stress of refugee women in Canada. Cortisol hormone was selected as a hormone associated with the tension and stress (stress hormone). Folk dance was selected because of its physical, national, and recreational importance.

\section{Research Objectives:}

This research aims to:

design a folk dance Expression program for refugee women in Canada and to find its effect on:

a- Some morphological and physiological variables (cortisol level) for refugee women.

b- The psychological stress of refugee women.

1- The effectiveness of the applied folk dance Expression program on morphological, physiological, psychological stress measures on the research sample of refugee women

2- Obtain self-Assessment on the folk dance Expression program from the research sample of refugee women. 


\section{Research hypotheses:}

1. There are statistically significant differences between the mean pre and post measurements in the morphological, physiological, and psychological stress variables of refugee women in favor of post measurements.

2. There is a positive effect of the application of the folk dance Expression program on the morphological, physiological, and psychological stress variables.

3- Positive self- Assessment of the folk dance Expression program from the research sample of refugee women.

\section{Search terms:}

\section{Folk dance:}

Folk dance is a dance developed by people in a certain country or region to reflect their life and that is transmitted from generation to generation. It has cultural roots and is characteristic of the common people of a country. (14)

\section{Dabke :}

Dabke is a native Levantine folk dance performed by the Lebanese, Jordanians, Syrians, Palestinians, Israeli Arabs, Iraqis, Turks and Egyptians in the Sinai Peninsula. Dabke combines circle dance and line dancing and is widely performed at weddings and other joyous occasions. The line forms from right to left and leader of the dabke heads the line, alternating between facing the audience and the other dancers. (41)

\section{Psychological stress}

Psychological stress is a particular relationship between the person and the environment that is appraised by the person as taxing or exceeding his or her resources and endangering his or her well-being. This relationship goes through two important phases that are (1) cognitive appraisals and (2) coping. (23)

\section{Research procedures:}

\section{Methodology:}

An experimental method was used to by having pre and post measurements of one experimental group.

\section{The research sample:}

- The research sample included refugee and displaced women for Canada due to the war conditions in their countries (Syria, Iraq, Palestine and Lebanon). One experimental group of 60 women was randomly chosen.

- A survey sample from the original research population, not form the research sample, consisting of (22) women, to answer an open question to find the axes of the physiological stress scale for the refugee women

\section{Criteria for sample selection:}

- Sample members did not participate in other experiments during the application of the program in order not to affect the research results.

- Punctuality of sample members in the program during the study period.

- Alcohol, smoking, or sedative drugs are prohibited during the study period 


\section{Research scope:}

Spatial scope: The study was conducted in the gymnasium of London Islamic Mosque in Canada (Ontario Province, Canada).

- Morphological, physiological and physical measurements were performed in a room attached to the Gymnasium of London Islamic Mosque in Canada in the presence of a physician to supervise the measurements.

Time scope: The program was implemented from $1 / 9 / 2017$ to $1 / 12 / 2017$

\section{Preparation and setting of research tools}

First: Measurements of morphological and physiological variables:

* Morphological Measurements: Attachment (2)

- Measuring the total body Height to the nearest $\mathrm{cm}$.

- Measurement of Body Weight in kg.

- Calculation of the Body Mass Index using the following equation:

Weight $(\mathrm{kg}) /$ square height $\left(\mathrm{cm}^{2}\right)$.

\section{* Physiological Measurements: Attachment (2)}

- Blood pressure. (mm mercury)

- Blood sugar. (mmol/L)

- Cortisol hormone concentration (in saliva swabs) morning and evening (ng/ml)

\section{Devices used:}

1- Restameter device for measuring height and medical scale for measuring weight.

2- Blood pressure monitor.

3- Blood glucose instrument.

4- Device for measuring cortisol hormone.

\section{Second: measurement of psychological stress:}

\section{Steps to set up the scale:}

The purpose of the scale: The measure aims to identify and measure the psychological stress experienced by refugee women.

- Determining the axes of the scale: Asking an open question to the survey sample: "What are the stress you face in your new life?"

A set of axes was determined (9 axes). After surveying scientific references that dealt with psychological stress such as (9), (1), (29) and reviewing previous studies such as the study of Khaled Al-Hashemi (2011) (20) Abd El-Hadi Al-Qahtani (2013) (2), Amani Mahmoud (2018) (5), A set of axes related to psychological stress was identified, namely:

1- Political stress (crises and disasters). 2- Economic stress.
3- Family stress.
4- community stress.
5- Work stress.
6- Study stress.
7- Health stress.
8- Emotional stress.

9- Personal stress. 
- Defining the phrases of the scale: by referring to the scientific references and previous studies in the field of psychology, the phrases of the scale were set, which consisted of (61) phrase.

\section{Scientific coefficients for Psychological Stress scale:}

\section{Validation of the scale:}

- Content validation: The scale (consisting of 61 phrases) was presented to (11) experts and arbitrators in the field of psychology (attachment 1) to put their opinion on the scale phrases in its preliminary form to know its suitability. The primary scale was modified according to the recommendation of experts by rephrasing, separating, or deleting some phrases and axes. The modified scale consisted of 8 axes and 52 phrases became valid for application in its final form as shown in Table (1). A balance scale of five points has been set (very large degree - large degree - medium degree low degree - none) so that it gives a very large (5 degrees), Large (4 degrees), medium (3 degrees), low (2 degrees), none (no degrees), and therefore the final degrees of the scale become (260 degrees) (attachment 3).

- The validity of internal consistency: The validity of the scale was calculated by internal consistency by calculating the correlation of the phrase with the axis that falls under it and the correlation of the axis with the overall degree of the scale as shown in the following tables: -

Table (1)

Validation the internal consistency of the Psychological Stress scale phrases

for refugee women $(n=22)$

\begin{tabular}{|c|c|c|c|c|c|c|c|c|c|}
\hline No & $\begin{array}{c}\text { Correlation } \\
\text { coefficient }\end{array}$ & No & $\begin{array}{c}\text { Correlation } \\
\text { coefficient }\end{array}$ & No & $\begin{array}{c}\text { Correlation } \\
\text { coefficient }\end{array}$ & No & $\begin{array}{c}\text { Correlation } \\
\text { coefficient }\end{array}$ & No & $\begin{array}{c}\text { Correlation } \\
\text { coefficient }\end{array}$ \\
\hline \multicolumn{2}{|c|}{$\begin{array}{c}\text { First axis: } \\
\text { economic stress }\end{array}$} & 4 & $0.425^{*}$ & 9 & $0.423 *$ & 3 & $0.432 *$ & 2 & $0.447 *$ \\
\hline 1 & $0.424^{*}$ & 5 & $0.424^{*}$ & 10 & $0.436 *$ & 4 & $0.595 * *$ & 3 & $0.478^{*}$ \\
\hline 2 & $0.430 *$ & 6 & $0.555 * *$ & 11 & $0.612 * *$ & 5 & $0.429 *$ & 4 & $0.594 * *$ \\
\hline 3 & $0.722 * *$ & \multicolumn{2}{|c|}{$\begin{array}{c}\text { Third axis: } \\
\text { Community stress }\end{array}$} & \multicolumn{2}{|c|}{$\begin{array}{c}\text { Forth axis: work } \\
\text { stress }\end{array}$} & \multicolumn{2}{|c|}{$\begin{array}{c}\text { Sixth axis: heath } \\
\text { stress }\end{array}$} & 5 & $0.445^{*}$ \\
\hline 4 & $0.687 * *$ & 1 & $0.428^{*}$ & 1 & $0.512 *$ & 1 & $0.457 *$ & 6 & $0.739 * *$ \\
\hline 5 & $0.716 * *$ & 2 & $0.522 *$ & 2 & $0.432 *$ & 2 & $0.549 * *$ & 7 & $0.555 * *$ \\
\hline 6 & $0.471^{*}$ & 3 & $0.429^{*}$ & 3 & $0.461^{*}$ & 3 & $0.655^{* *}$ & 8 & $0.471 *$ \\
\hline 7 & $0.422 *$ & 4 & $0.451^{*}$ & 4 & $0.530 *$ & 4 & $0.678 * *$ & 9 & $0.453^{*}$ \\
\hline \multicolumn{2}{|c|}{$\begin{array}{c}\text { Second axis: family } \\
\text { stress }\end{array}$} & 5 & $0.472 *$ & 5 & $0.481 *$ & 5 & $0.424 *$ & 10 & $0.480^{*}$ \\
\hline 1 & $0.590 * *$ & 6 & $0.591 * *$ & \multicolumn{2}{|c|}{$\begin{array}{c}\text { Fifth axis: study } \\
\text { stress }\end{array}$} & 6 & $0.424 *$ & 11 & $0.542 * *$ \\
\hline 2 & $0.734 * *$ & 7 & $0.462 *$ & 1 & $0.866^{* *}$ & \multicolumn{2}{|c|}{$\begin{array}{c}\text { Seventh axis: } \\
\text { emotional stress }\end{array}$} & 12 & $0.612 * *$ \\
\hline 3 & $0.485^{*}$ & 8 & $0.687 * *$ & 2 & $0.463 *$ & 1 & $0.688 * *$ & & \\
\hline
\end{tabular}

* "R" tabular Significance at level $0.05=0.423, * *$ at level $0.01=0.537$

From Table (1) that there is a significance in the value of the correlation coefficient " $\mathrm{R}$ " for the phrases of the psychological stress scale, while there is no significance did not appear in all phases of the first axis: political pressure) and the phrase No. (5) in the second axis and the phrase No. (3) in the third axis and phrase No. (10) in the fourth axis. Therefore, these phrases that are not related to the measure of psychological stress of refugee women are deleted. 
Table (2)

Validation the internal consistency of the Psychological Stress scale axes for refugee women $(n=22)$

\begin{tabular}{|c|c|c|c|c|c|}
\hline \multirow[t]{2}{*}{ No } & \multirow[t]{2}{*}{ stress scale axis } & \multicolumn{2}{|c|}{ Primary scale } & \multicolumn{2}{|c|}{ Final scale } \\
\hline & & $\begin{array}{c}\text { Correlation } \\
\text { coefficient }\end{array}$ & $\begin{array}{c}\text { No of } \\
\text { phrases }\end{array}$ & $\begin{array}{c}\text { Correlation } \\
\text { coefficient }\end{array}$ & $\begin{array}{c}\text { No of } \\
\text { phrases }\end{array}$ \\
\hline 1 & First Axis: Political stress & - & $\overline{6}$ & - & $\overline{\mathbf{0}}$ \\
\hline 2 & Second Axis: Economic stress & $0.443 *$ & 8 & $0.452 * *$ & 7 \\
\hline 3 & Third axis: Family stress & $0.581 * *$ & 7 & $0.708 * *$ & 6 \\
\hline 4 & Forth axis: Community stress & $0.932 * *$ & 12 & $0.759 * *$ & 11 \\
\hline 5 & Fifth axis: Work stress & $0.567 * *$ & 5 & $0.480 *$ & 5 \\
\hline 6 & Sixth axis: Study stress & $0.639 * *$ & 5 & $0.736 * *$ & 5 \\
\hline 7 & Seventh axis: Health stress & $0.761 * *$ & 6 & $0.761 * *$ & 6 \\
\hline 8 & Eighth axis: emotional stress & $0.643 * *$ & 12 & $0.723 * *$ & 12 \\
\hline
\end{tabular}

** "R" tabular Significance at level $0.05=0.423, * *$ at level $0.01=0.537$

From Table (2) that there is significance the correlation coefficient " $R$ " in the axes of the psychological stress scale in its final form after deleting the first axis (political stress that is still standing until now) and the phrases that are not related to the scale). The number of final phrases in the scale became 52. The correlation coefficient values ranged between $(0.452$ : 0.761 ), which are high and significant values and indicates the validity of the scale before applying the basic study on the research sample.

Stability of the scale: The Stability Coefficient (Cronbach Alpha) and Split-Half Reliability were used to calculate the reliability of the scale as shown in the following table:

Table (3)

Reliability coefficient for axes of psychological stress scale for refugee women $(n=22)$

\begin{tabular}{|c|c|c|c|c|c|}
\hline \multirow[b]{2}{*}{ No } & \multirow[b]{2}{*}{ Axes of the scale } & \multicolumn{2}{|c|}{ primary scale } & \multicolumn{2}{|c|}{ final scale } \\
\hline & & $\begin{array}{c}\text { Cronbach } \\
\text { Alpha } \\
\text { Stability } \\
\text { Coefficient }\end{array}$ & $\begin{array}{l}\text { Split-Half } \\
\text { Reliability } \\
\text { Coefficient }\end{array}$ & $\begin{array}{c}\text { Cronbach } \\
\text { Alpha } \\
\text { Stability } \\
\text { Coefficient }\end{array}$ & $\begin{array}{l}\text { Split-Half } \\
\text { Reliability } \\
\text { Coefficient }\end{array}$ \\
\hline 1 & First Axis: Economic stress & 0.565 & 0.627 & 0.721 & 0.692 \\
\hline 2 & Second Axis: Family stress & 0.055 & $\mathbf{0 . 0 3}$ & 0.675 & 0.624 \\
\hline 3 & Third axis: Community stress & 0.426 & 0.359 & 0.632 & 0.684 \\
\hline 4 & Forth axis: Work stress & 0.791 & 0.804 & 0.791 & 0.804 \\
\hline 5 & Fifth axis: Study stress & 0.892 & 0.712 & 0.892 & 0.712 \\
\hline 6 & Sixth axis: Health stress & 0.630 & 0.722 & 0.630 & 0.722 \\
\hline 7 & Seventh axis: emotional stress & 0.655 & 0.631 & 0.655 & 0.631 \\
\hline \multicolumn{2}{|c|}{ Total score for psychological stress scale } & 0.714 & 0.667 & 0.734 & 0.711 \\
\hline
\end{tabular}

Table (3) indicates the increase in the value of the stability coefficient in the psychological stress scale after deleting the unrelated phrases so that the value of the Cronbach Alpha Stability Coefficient become (0.734) and its range value in the axes of the scale ranged between (0.630: 0.892), and the value of Split-Half Reliability Coefficient was (0.711) and Its ranged value in the axes is between (0.624: 0.804$)$ and all are high values greater than 0.60 and approach the unit one, which indicates the stability of the scale of the scale before applying the basic study on the research sample of refugee women.

\section{Third: The Folk dance Expression Program:}

- Basis of developing the program: the following were considered:

- The program should be in consistent with the characteristics of the study sample in terms of age, gender and psychological state. 
- The program should consider the progression in motor performance from easy to difficult, as well as the gradual repetition.

- The program should consider the diversity in folk dances and style of performance.

- The unit of the program should have movements that includes all parts of the body.

- The program should consider individual differences.

- The general objectives of the program: It aims to identify the effectiveness of folk dance expression on some physiological variables and the cortisol hormone to relieve psychological stress of refugee women in Canada.

- Program content: The content of the program was determined after reviewing the scientific references such as (13), (32), (12), (28), (36), and scientific research such as Amani Mahmoud (2018) (5), Maram Mohamed (2018) (25), Maryam Hanna (2018) (26), Nawal Abd Al-Rahman (2018) (35), and analysing it to be appropriate to the goals that were set, and the characteristics of the sample so that the program includes spiritual sessions to support religious values and beliefs, and guiding sessions to support some of the characteristics and attributes such as Self-confidence and self-support, cooperation, planning for the future, relieving stress, anxiety, fear, and emotions, and coexistence with suffering and facing events, then the folk dance expressive motor activity, then relaxation exercises.

Table (4)

Number of training units and program time

\begin{tabular}{c|c|c}
\hline No & data & Time distribution \\
\hline 1 & The total duration of the program & 3 months \\
\hline 2 & The number of weeks in the program & 12 weeks \\
\hline 3 & No of units per week & 3 units \\
\hline 4 & The total number of units in the program & $\mathbf{3 6}$ units \\
\hline 5 & Unit time & 4320 minutes \\
\hline 6 & The total time for the program is 4320 minutes & $\mathbf{7 2}$ hours \\
\hline 7 & The total time of the program is & ped \\
\hline
\end{tabular}

- Methods of Program presentation: A method of dialogue and discussion was used, which depends on the participation of women in a dialogue on a specific topic and goals, as well as the use of the lecture style, and the method of observation and the practical notes. The performance of women is observed and dialogue and discussion were used in the application of the program. Dialogue and discussion aim to creating a converging and cooperative society surrounded by an atmosphere of intimacy and affection among them, which can take advantage of similar situations and try to think collectively to reach solutions to the problems facing them.

\section{- Presenting the content of the program was presented to experts in the field of motor expression:}

The program was presented to a group of experts and specialists in the field of motor expression and psychology and their opinions, and in light of their observations, modifications was made in the formulation and arrangement of some elements, and after making the required modifications, the content of the program in its final form became valid for application to the basic study sample. Attachment (4)

Fourth: Self- Assessment form on the folk dance Expression program for refugee women as a whole 
- The aim of the form: To identify the extent of success and effectiveness of the program in achieving its goals through the views of the research sample in all aspects of the program (its objectives, organizational aspect, and number of hours)

- Formulation of the parameters of the form: The parameters of the form were formulated as expressions through which it is possible to indicate the extent to which its objectives and effectiveness are achieved. The formulation of the expressions in the selfAssessment form took into consideration the clarity and ease of the expressions and the accuracy of the formulation.

- Validity of the form: To ensure the validity of the form, it was presented to the experts and they unanimously agreed on the integrity and validity of its parameters. Attachment (5)

\section{Program executive procedures:}

- Homogeneity of the sample population: Homogeneity was ensured among the members of the experimental group sample in the following variables:

- Homogeneity between the experimental group in the main (age, height and weight) and physiological variables: Homogeneity between the experimental group in the basic variables (age, height and weight) was assured in the first week of the program as shown in the following table.

Table (5)

Homogeneity of the research sample in the anthropometric and physiological measurements of refugee women in Canada $(n=60)$

\begin{tabular}{|c|c|c|c|c|c|c|c|c|}
\hline No & \multicolumn{2}{|l|}{ Measurements } & $\begin{array}{l}\text { Min } \\
\text { value }\end{array}$ & $\begin{array}{l}\text { Max } \\
\text { value }\end{array}$ & Mean & $\begin{array}{c}\text { St. } \\
\text { deviation }\end{array}$ & $\begin{array}{c}\text { skewness } \\
\text { coefficient } \\
\text { s }\end{array}$ & $\begin{array}{c}\text { Kurtosis } \\
\text { coefficients }\end{array}$ \\
\hline 1 & Age (years) & & 40 & 55 & 47.55 & 4.656 & -0.032 & -1.272 \\
\hline 2 & Height (cm) & & 155 & 180 & 163.50 & 5.727 & 0.612 & 0.434 \\
\hline 3 & Weight (Kg) & & 77 & 100 & 85.57 & 5.074 & 0.417 & 0.569 \\
\hline 4 & Body mass Index (kg/cm2) & & 30.86 & 34.5 & 31.99 & 0.802 & 1.359 & 1.747 \\
\hline 5 & Middle circumference $(\mathrm{cm})$ & & 95 & 110 & 100.47 & 3.332 & 0.816 & 0.665 \\
\hline 6 & Pelvic circumference $(\mathrm{cm})$ & & 104 & 120 & 110.23 & 4.006 & 0.458 & -0.295 \\
\hline 7 & $\begin{array}{l}\text { Difference of middle to pelvic } \\
\text { circumference }\end{array}$ & & 0.86 & 0.96 & 0.91 & 0.029 & -0.054 & -0.923 \\
\hline \multirow{2}{*}{8} & \multirow{2}{*}{ Blood Pressure (mm Hg) } & Systolic & 128 & 150 & 140.23 & 6.440 & -0.439 & -1.142 \\
\hline & & Diastolic & 85 & 100 & 92.52 & 5.216 & 0.079 & -1.469 \\
\hline 9 & $\begin{array}{c}\text { Blood glucose concentration } \\
(\mathrm{mmol} / \mathrm{L})\end{array}$ & & 5.9 & 6.8 & 6.30 & 0.323 & 0.212 & -1.508 \\
\hline \multirow{2}{*}{10} & \multirow{2}{*}{$\begin{array}{c}\text { Cortisol hormone concentration } \\
(\mathbf{n g} / \mathrm{ml})\end{array}$} & morning & 18 & 27 & 23.60 & 2.241 & -0.160 & -0.634 \\
\hline & & evening & 6 & 12 & 9.80 & 1.582 & -0.483 & -0.594 \\
\hline
\end{tabular}

Table (5) shows the lowest and highest value, the arithmetic mean and the standard deviation for the anthropometric and physiological measurements. The skewness coefficient came close to zero, and the Kurtosis coefficient are limited to $( \pm 3)$, which indicates the moderation of the values and homogeneity of the sample of the refugee sample.

\section{Program Implementation:}

The program was applied to the basic research sample from (1/9/2017) to (1/12/2017) according to the following time plan:

\section{Program timeline:}

The implementation of the program lasted (12) weeks. Meetings with the experimental group three units per week, each unit time is two hours. 


\section{Research measurements:}

\section{A- Pre measurements:}

Pre measurements for morphological and physiological variables and psychological stress of refugee women in the gymnasium attached to the Islamic Mosque in Canada in the presence with a doctor supervising morphological and physiological measurements.

\section{B-Basic study:}

The Folk dance Expression Program was applied to the experimental group (attachment 4), and the study was carried out from (1/9/2017) to (1/12/2017) for a period of (12) weeks at three units per week. A topic is set for the 3 units every week (stress - challenging and facing events and problems - anxiety and overcoming it - coexistence with suffering - cooperation fear and overcoming it - emotional relief - self-confidence and self-support - relaxation planning for the future). Each unit is done as follows:

- Guidance session: Welcoming the members of the group and make the afternoon prayer in congregation, then a discussion and dialogue between the researcher and the members of the group on the topic of unity.

- Warming up: where a set of exercises are performed, whether free or with tools, single and bilateral. The women group followed the performance of the exercises to prepare the body for the next part of the unit.

- The Folk dance expressive part: the researcher gives an overview of folk dance, types of dabke dances in the Levant countries and the difference between them, focusing on the common fundamentals between them, the nature of the music, its characteristics, and the performance that characterizes the chosen dabke dance (the daluna dance) and training on the motor constituents and kinetic performance of this dance.

- Relaxation: At the end of each unit, a set of exercises is performed to relax and calm down.

It was taken into consideration that the program included an entertainment day (Syrian day Lebanese day - Iraqi day - Palestinian day) every three weeks in which each group of women presented their culture and arts and attended with their families wearing in their finest customs. Organizing this day helped to discover skills and activities that can help these women to get a source of income such as (Syrian, Lebanese and Iraqi meals - handicrafts and embroidery). Commitment to organise this day to become the International Day for Multiple Cultures in Canada.

\section{C- Post measurements:}

After completing the implementation of The Folk dance Expression Program, post measurements of morphological and physiological variables, and psychological stress were taken for each participant of the study sample and with the same conditions that were followed in the pre measurements.

Statistical analysis: The data was processed using the IBM SPSS Statistics 20 to obtain the following statistical processors: -

- Percentage.

- Arithmetic mean

- Standard deviation.

- Skewness coefficient

- Kurtosis coefficient

- Pearson correlation coefficient.

- Cronbach Alpha Stability Coefficient

- Split-Half Reliability Coefficient 
- T-test for independent samples.

- Eta Squared

- Effect size.

\section{Results and discussion:}

A- Results of the first hypothesis, which states that "There are statistically significant differences between the mean pre and post measurements in the morphological, physiological, and psychological stress variables of refugee women in favor of post measurements".

To verify the validity of this hypothesis, the significant differences between the pre and post measurements of the experimental group in morphological variables (weight, body mass index, middle and pelvic circumference) and physiological variables (systolic and diastolic blood pressure, blood sugar level and cortisol hormone) was calculated as shown in Table (6) and Figure (1). Attachment (6)

Table (6)

Significant differences between the pre and post measurements of the experimental group in morphological variables and physiological variables $(n=60)$

\begin{tabular}{|c|c|c|c|c|c|c|c|c|c|c|}
\hline \multirow[b]{2}{*}{ No } & \multirow{2}{*}{\multicolumn{2}{|c|}{ Measurement }} & \multicolumn{2}{|c|}{ Pre measure } & \multicolumn{2}{|c|}{ Post measure } & \multicolumn{2}{|c|}{ difference } & \multirow{2}{*}{$\begin{array}{c}\text { Calculated } \\
\text { t value }\end{array}$} & \multirow{2}{*}{$\begin{array}{c}\text { Improvement } \\
\%\end{array}$} \\
\hline & & & $\mathbf{x -}$ & St. D & $\mathrm{x}-$ & St. D & $\mathbf{x -}$ & St. D & & \\
\hline 1 & \multicolumn{2}{|c|}{ Weight (Kg) } & 85.57 & 5.07 & 71.57 & 4.62 & -14.00 & 1.61 & $67.563 * *$ & 16.36 \\
\hline 2 & \multicolumn{2}{|c|}{ Body mass Index $(\mathrm{kg} / \mathrm{cm} 2)$} & 31.99 & 0.80 & 26.72 & 0.76 & -5.27 & 0.60 & 68.364** & 16.48 \\
\hline 3 & \multicolumn{2}{|c|}{ Middle circumference $(\mathrm{cm})$} & $\mathbf{1 0 0 . 4 7}$ & 3.33 & 82.73 & 3.47 & -17.73 & 2.43 & $56.581 * *$ & $\mathbf{1 7 . 6 5}$ \\
\hline 4 & \multicolumn{2}{|c|}{ Pelvic circumference $(\mathrm{cm})$} & 110.23 & 4.01 & 98.70 & 2.71 & -11.53 & 2.87 & $31.097 * *$ & 10.46 \\
\hline 5 & \multicolumn{2}{|c|}{$\begin{array}{l}\text { Difference between middle and } \\
\text { pelvic circumference }\end{array}$} & 9.77 & 3.29 & 15.97 & 2.81 & 6.20 & 3.04 & $15.793 * *$ & 63.48 \\
\hline 6 & \multicolumn{2}{|c|}{ Systolic Blood Pressure (mm Hg) } & 140.23 & 6.44 & 122.57 & 4.14 & -17.67 & 3.70 & $36.948 * *$ & 12.60 \\
\hline 7 & \multicolumn{2}{|c|}{ Diastolic Blood Pressure (mm Hg) } & $\mathbf{9 2 . 5 2}$ & 5.22 & 82.82 & 4.18 & -9.70 & 2.57 & $29.277 * *$ & 10.48 \\
\hline 8 & \multicolumn{2}{|c|}{ fasting blood glucose } & 6.30 & 0.32 & 5.35 & 0.17 & -0.95 & 0.26 & $28.542 * *$ & 15.13 \\
\hline \multirow[t]{2}{*}{9} & \multirow{2}{*}{$\begin{array}{c}\text { Cortisol hormone } \\
\text { concentration } \\
(\mathbf{n g} / \mathbf{m l})\end{array}$} & morning & 23.60 & 2.24 & 20.30 & 3.10 & -3.30 & 3.44 & $7.43 * *$ & 13.98 \\
\hline & & evening & 9.80 & 1.58 & 3.19 & 0.53 & -6.61 & 1.61 & $31.85 * *$ & 67.47 \\
\hline
\end{tabular}

** " $\mathrm{t}$ " significant at $0.05=2.00$, at $0.01=2.66$

From Table (6) and Figure (1) attachment (6), that there are statistically significant differences in the value of calculated " $t$ " between the pre and post measurement in physiological measurements. Improvement percentage ranged between $(10.46 \%: 67.47 \%)$ in favor of the post measurements in refugee women.

These results are due to the fact that the proposed The Folk dance Expression Program has contributed to an improvement in the laboratory measurement of the concentration of the cortisol hormone in the sample, and this is consistent with what was indicated by both Hussein Heshmat and Abd El-Kafi Abd El-Aziz (2010) that physical training increase nerve signals and that the sports exercise improves the mood of the individual (19:300).

Our results are also in consistent with the results of the study of El-Sayed Derbala (1999) (11), Alia Shams El-Din (2004) (4), Taylor B. et al. (2005) (40), Amani Mahmoud (2018) (5) who emphasized the effect of athletic motor performance on some morphological and physiological variables and reducing levels of some hormones including cortisol hormone.

Moreover, the significance of the differences between pre and post measurement in psychological stress, the value of " $\mathrm{t}$ " and the percentage of improvement was calculated as shown in Table (7) and Figure (2). Attachment (6) 
Table (7)

Significant differences between the pre and post measurements of the experimental group in psychological stress for refugee women $(n=60)$

\begin{tabular}{|c|c|c|c|c|c|c|c|c|c|}
\hline \multirow[b]{2}{*}{ No } & \multirow[b]{2}{*}{ Measurement } & \multicolumn{2}{|c|}{ Pre measure } & \multicolumn{2}{|c|}{ Post measure } & \multicolumn{2}{|c|}{ difference } & \multirow{2}{*}{$\begin{array}{l}\text { Calculated } \\
\text { t value }\end{array}$} & \multirow{2}{*}{$\begin{array}{c}\text { Improvement } \\
\%\end{array}$} \\
\hline & & $\mathbf{x -}$ & St. D & $\mathbf{x}-$ & St. D & $\mathbf{x}-$ & $\begin{array}{c}\text { St. } \\
\text { D }\end{array}$ & & \\
\hline$\overline{11}$ & $\begin{array}{c}\text { First Axis: Economic } \\
\text { stress }\end{array}$ & 27.33 & 1.10 & 14.42 & 1.73 & -12.92 & 1.79 & $55.963 * *$ & 47.26 \\
\hline 2 & $\begin{array}{c}\text { Second Axis: Family } \\
\text { stress } \\
\end{array}$ & 9.93 & 1.80 & 9.90 & 1.58 & -0.03 & 1.16 & 0.222 & 0.34 \\
\hline 3 & $\begin{array}{c}\text { Third axis: Community } \\
\text { stress }\end{array}$ & 17.80 & 2.40 & 18.38 & 2.36 & 0.58 & 2.33 & 1.938 & 3.28 \\
\hline 4 & Forth axis: Work stress & 12.23 & 1.42 & 9.87 & 1.49 & -2.37 & 2.07 & $8.871 * *$ & 19.35 \\
\hline 5 & $\begin{array}{c}\text { Fifth axis: Study stress } \\
\text { circumference }\end{array}$ & 11.02 & 0.91 & 12.12 & 1.24 & 1.10 & 1.34 & $6.375 * *$ & 9.98 \\
\hline 6 & Sixth axis: Health stress & 13.38 & 1.35 & 10.97 & 1.35 & -2.42 & 1.33 & $14.060 * *$ & 18.06 \\
\hline 7 & $\begin{array}{c}\text { Seventh axis: emotional } \\
\text { stress }\end{array}$ & 20.02 & 2.61 & 20.32 & 2.51 & 0.30 & 1.62 & 1.436 & 1.50 \\
\hline \multicolumn{2}{|r|}{ Total degree of the scale } & 111.72 & 7.21 & 95.97 & 6.39 & -15.75 & 5.66 & $21.559 * *$ & 14.10 \\
\hline
\end{tabular}

** “t” significant at $0.05=2.00$, at $0.01=2.66$

Table (7) and Figure (2) attachment (6) indicate that there are statistically significant differences in the value of calculated " $t$ " between the pre and post measurement in some axes of the psychological stress scale. The improvement in economic stress was $47.26 \%$, work stress was $19.35 \%$, and health stress was $18.06 \%$. The overall score of the scale was $14.10 \%$ in favor of post measurement for refugee women.

The researchers believe that the practice of motor performance of the Dabke dances with its positive effect on some physiological variables contributed to alleviating some of the health stress.

These results are due to the fact that the proposed Folk dance Expression Program has contributed to reducing the percentage of psychological stress among the sample members. Lynn Goldberg and Diane (2002) emphasize that physical activity raises the mood and improves the psychological state and makes individuals more able to think positively and focus and increases their feeling of happiness (24: 330,347). Positive Psychology researchers also indicated that practicing sporting activities, including motor expression increase the flow state and vitality. The flow state is the psychological state that one finds himself able to use and employ his personal skills to the maximum extent possible when facing difficult circumstances (29: 93), and this is confirmed by the study of Wafaa Al-Mahi (2000) (42) that the motor performance of the movement expression can achieve the utmost enjoyment and joy. With this result, the first hypothesis is validated.

B- Results of the second hypothesis, which states that "There is a positive effect of the application of the folk dance Expression program on the morphological, physiological, and psychological stress variables of refugee women".

To verify the validity of this hypothesis, the value of " $t$ ", the correlation coefficient and the effect size for both morphological and physiological variables were calculated from Table 8 and Figure (3) Attachment (6). 
Table (8)

The effect of the The Folk dance Expression Program on the morphological and physiological measurements of refugee women $(n=60)$

\begin{tabular}{|c|c|c|c|c|c|c|c|}
\hline \multirow[b]{2}{*}{ No } & \multirow{2}{*}{\multicolumn{2}{|c|}{ Measurement }} & \multirow[b]{2}{*}{$\begin{array}{c}\text { Calculated } \\
\text { (t) }\end{array}$} & \multirow[b]{2}{*}{$\begin{array}{c}\text { Correlation } \\
\text { Coefficient } \\
\text { (r) }\end{array}$} & \multicolumn{3}{|c|}{ Effect size } \\
\hline & & & & & $\begin{array}{c}\text { Eta } \\
\text { Squared }\end{array}$ & $\begin{array}{c}\text { Value of } \\
\text { Effect size }\end{array}$ & $\begin{array}{l}\text { Amount of } \\
\text { Effect size }\end{array}$ \\
\hline 1 & \multicolumn{2}{|c|}{ Weight (Kg) } & 67.563 & 0.949 & 0.987 & 2.774 & High \\
\hline 2 & \multicolumn{2}{|c|}{ Body mass Index (kg/cm2) } & 68.364 & 0.708 & 0.988 & 6.743 & High \\
\hline 3 & \multicolumn{2}{|c|}{ Middle circumference $(\mathrm{cm})$} & 56.581 & 0.746 & 0.982 & 5.204 & High \\
\hline 4 & \multicolumn{2}{|c|}{ Pelvic circumference $(\mathrm{cm})$} & 31.097 & 0.697 & 0.942 & 3.124 & High \\
\hline 5 & \multicolumn{2}{|c|}{$\begin{array}{l}\text { Difference between middle and pelvic } \\
\text { circumference }\end{array}$} & 15.793 & 0.512 & 0.809 & 2.013 & High \\
\hline 6 & \multicolumn{2}{|c|}{ Systolic Blood Pressure (mm Hg) } & 36.948 & 0.842 & 0.959 & 2.682 & High \\
\hline 7 & \multicolumn{2}{|c|}{ Diastolic Blood Pressure (mm Hg) } & 29.277 & 0.873 & 0.936 & 1.901 & High \\
\hline 8 & \multicolumn{2}{|c|}{ FBG } & 28.542 & 0.603 & 0.932 & 3.283 & High \\
\hline \multirow{2}{*}{9} & \multirow{2}{*}{$\begin{array}{c}\text { Cortisol hormone } \\
\text { concentration } \\
(\mathbf{n g} / \mathbf{m l})\end{array}$} & morning & 7.43 & 0.201 & 0.483 & 1.213 & High \\
\hline & & evening & 31.85 & 0.118 & 0.945 & 5.461 & high \\
\hline
\end{tabular}

$*$ Effect size $=0.2$ Poor, 0.5 Medium, 0.8 High.

*ETA squared $=$ less than 0.09 weak, greater than 0.14 is high

Table (8) and Figure (3) attachment (6) indicate that the effect of the folk dance Expression program on physiological measurements was high, where the values of the effect size ranged between $(1.901,6.743)$, and the values of the squared ETA ranged between $(0.809,0.988)$ which are High values greater than 0.14 . This indicates the effectiveness of the program the folk dance and its effect on the level of the cortisol hormone to reduce the psychological stress resulting from the alienation of refugee women. Psychological stress lead to mental stress and a sense of anxiety and depression.

The physiological response to psychological stress is characterized by secretions of some hormones to stimulate the physiological functions necessary to face the danger to which a person may be exposed. As a result of the recurrence of these secretions, the activity of normal physiological functions such as breathing, or heart rate increases more than the norm and causing other pathological symptoms. (38: 45-46).

Ghosun Fadel (2016) believes that cortisol hormone is considered as a marker of the state of tension, irritability and exhaustion that the individual is exposed to in his life in general. (15)

The results of this study are consistent with the results of the Akandere and Demir study (2011) (27), Wegner M. et al. (2018) (44), Ameri M. et al. (2019) (6)) who indicated that training, movement and dance therapy has a positive effect on Psychological development, relieve of anxiety and depression, reduce cortisol levels, and develop thinking skills. (27: 651).

Moreover, the value of " $t$ ", the correlation coefficient and the effect size of the psychological stress were calculated, as shown in Table (9) and Figure (4) attachment (6). 
Table (9)

The effect of the folk dance Expression program on psychological stress scale for refugee women $(n=60)$

\begin{tabular}{|c|c|c|c|c|c|c|}
\hline \multirow[b]{2}{*}{ No } & \multirow[b]{2}{*}{ Measurement } & \multirow[b]{2}{*}{$\begin{array}{c}\text { Calculated } \\
(\mathbf{t})\end{array}$} & \multirow[b]{2}{*}{$\begin{array}{c}\text { Correlation } \\
\text { Coefficient } \\
\text { (r) }\end{array}$} & \multicolumn{3}{|c|}{ Effect size } \\
\hline & & & & $\begin{array}{c}\text { Eta } \\
\text { Squared }\end{array}$ & $\begin{array}{c}\text { Value of } \\
\text { Effect size }\end{array}$ & $\begin{array}{c}\text { Amount } \\
\text { of Effect } \\
\text { size }\end{array}$ \\
\hline 1 & First Axis: Economic stress & 55.963 & 0.264 & 0.982 & 8.764 & High \\
\hline 2 & Second Axis: Family stress & 0.222 & 0.771 & 0.001 & 0.019 & low \\
\hline 3 & Third axis: Community stress & 1.938 & 0.520 & 0.060 & 0.245 & low \\
\hline 4 & Forth axis: Work stress & 8.871 & 0.009 & 0.572 & 1.627 & High \\
\hline 5 & Fifth axis: Study stress & 6.375 & 0.254 & 0.408 & 1.005 & High \\
\hline 6 & Sixth axis: Health stress & 14.060 & 0.516 & 0.770 & 1.786 & High \\
\hline \multirow[t]{2}{*}{7} & Seventh axis: emotional stress & 1.436 & 0.801 & 0.034 & 0.117 & High \\
\hline & Total degree of the scale & 21.559 & 0.660 & 0.887 & 2.296 & low \\
\hline
\end{tabular}

*Effect size $=0.2$ Poor, 0.5 Medium, 0.8 High.

*ETA squared = less than 0.09 weak, greater than 0.14 is high

Table (9) and Figure (4) attachment (6) indicates The effect of the folk dance Expression program on the psychological stress scale was between weak and high, where the values of the effect size ranged between $(0.019,8.764)$, and the values of the squared ETA ranged between $(0.001,0.982)$ which indicates the effectiveness of the folk dance Expression program and its effect on the level of the cortisol hormone to reduce the psychological stress of refugee women.

Movement expression is one of the sporting activities that help in achieving the goal of developing an integrated personality through self-realization and it is affected by the individual's psychological state. The skill performance in Movement expression depends on the motor sense. The motor sense is the individual's ability to control the postures of his body and changes in the space and the speed of response to muscular work and the continuation of this work in a compatible framework. Movement expression also depends on attention and the high ability to focus to show innovative capabilities and to express feelings and emotions in the form of a dynamic performance that is characterized by beauty, agility and smoothrunning. Therefore, Movement expression affects and is affected by the psychological power of the individual. (10: 76) (39: 215).

Osama Rateb (2000) points out that in order for an individual to face stresses and overcome them, he must have a deep understanding of the stresses and the importance of controlling them. He must be able to analyze the degrees of stresses in his life and plan to completely eliminate them and reduce their levels by following several steps such as improving the environment in which the individual lives, health care, the use of plans to reduce mental stress, adaptation to negative elements in the personality of the individual, and use plans to reducing psychological stress. (37:212). This is what the two researchers applied during the research by discovering the skills and competencies of the research sample to invest them to obtain job opportunities and following up their health status and maintaining their dynamic performance and health, as well as strengthening the ties between the sample members through guiding sessions and emotional relief between them. With this result, the second hypothesis is validated.

C- Results of the third hypothesis, which states:"Positive self- Assessment of the folk dance Expression program from the research sample of refugee women." To verify the validity of this hypothesis, the frequency and percentages of self- Assessment of refugee women on the program were calculated, as shown in the following table. 
Table (10)

Frequency and percentages of the self- Assessment form of refugee women on the folk dance expression program.

\begin{tabular}{|c|c|c|c|c|c|c|c|}
\hline \multirow{2}{*}{ No } & \multirow[t]{2}{*}{ phrases } & \multicolumn{2}{|c|}{ Yes } & \multicolumn{2}{|c|}{ To some degree } & \multicolumn{2}{|c|}{ No } \\
\hline & & $\mathbf{F}$ & $\%$ & $\mathbf{F}$ & $\%$ & $\mathbf{F}$ & $\%$ \\
\hline & The program helped me in & & & & & & \\
\hline 1 & $\begin{array}{l}\text { A sense of belonging and patriotism through the folk } \\
\text { dance Expression program }\end{array}$ & 60 & 100 & & & & \\
\hline 2 & $\begin{array}{l}\text { The dynamic performance of folk dances contributed } \\
\text { to reducing my weight. }\end{array}$ & 60 & 100 & & & & \\
\hline 3 & Integrity and affinity within the group & 50 & 83.3 & 10 & 16.7 & & \\
\hline 4 & Appreciate the importance of teamwork. & 55 & 91.6 & 5 & 8.4 & & \\
\hline 5 & $\begin{array}{c}\text { Developing my skills that can help me raise my } \\
\text { economic level. }\end{array}$ & 60 & 100 & & & & \\
\hline 6 & $\begin{array}{l}\text { My knowledge of the methods that can get me out of } \\
\text { my ordeal }\end{array}$ & 55 & 91.6 & 5 & 8.4 & & \\
\hline 7 & Find solutions to my problems. & 50 & 83.3 & 10 & 16.7 & & \\
\hline 8 & $\begin{array}{l}\text { Learn about the legal channels that I must address to } \\
\text { face many problems. }\end{array}$ & 60 & 100 & & & & \\
\hline 9 & Improve myself and my family health & 60 & 100 & & & & \\
\hline 10 & Increased my self-confidence to face life situations & 51 & 85 & 9 & 15 & & \\
\hline 11 & $\begin{array}{l}\text { Realize the importance of emotional relief and } \\
\text { conversation in the group. }\end{array}$ & 50 & 83.3 & 10 & 16.7 & & \\
\hline 12 & $\begin{array}{l}\text { Benefiting from the experiences of other women in } \\
\text { facing repeated situations }\end{array}$ & 55 & 91.6 & 5 & 8.4 & & \\
\hline 13 & Increased ability to self-esteem. & 49 & 81.6 & 11 & 18.4 & & \\
\hline 14 & $\begin{array}{l}\text { Realizing the necessity of being closer to God to face } \\
\text { adversity. }\end{array}$ & 60 & 100 & & & & \\
\hline 15 & Feeling of suspense throughout the program & 56 & 93.3 & 4 & 6.7 & & \\
\hline 16 & $\begin{array}{c}\text { Knowing the effectiveness of the programs that } \\
\text { support refugees }\end{array}$ & 60 & 100 & & & & \\
\hline
\end{tabular}

From Table (10) the research sample of the refugee women in the program agreed with a percentage ranging from $81.6 \%$ to $100 \%$ which confirms the objective of this form to identify the success and effectiveness of the program and achieve its goals. The research sample in this form indicated their interest in knowing the legal channels to address to face their problems. The results of the form also emphasized that this program helped to develop the skills that help in raising the economic level, improving the health status, increasing selfconfidence in facing life situations, and realizing the necessity of be closer to God to face adversity.

\section{Conclusions and recommendations}

\section{Conclusions:}

In light of the research objectives and hypotheses, and based on its results, the following conclusions was extracted:

1- The folk dance Expression program improved the morphological variables (weight, body mass index, middle and pelvic circumference) and physiological variables (systolic and diastolic blood pressure, blood sugar level and cortisol hormone). Improvement percentage ranged between (10.46\%: 67.47\%) in favor of post measurement.

2- The folk dance Expression program relieved some psychological stresses as economic stress improved by $47.26 \%$, work stress improved by $19.35 \%$, health stress improved by $18.06 \%$. The overall score of the scale improved by $14.10 \%$ in favor of post measurements. 
3- The self-Assessment of the program was positive, as the research sample of refugee women agreed on the program at a rate ranging from $(81.6 \%$ to $100 \%)$.

4- Assigning a day each year dedicated to disseminating different Arab cultures which contain a set of activities that help to stand by the Arab refugees under the name "International Exhibition of Multiple Cultures".

\section{Recommendations:}

In light of the results of this research, the following recommendations presented:

1- The necessity of paying attention to measuring psychological stress for different groups of society with the aim of identifying the different responses to psychological stress and good planning to overcome it.

2- Caring for refugees, solving their problems, providing health care, psychological support, and programs for solving their problems that result from wars.

3- Preparing more studies on refugees and providing more rehabilitation programs to help them enter the labor market.

4- Setting a comprehensive database on refugees in each country and monitoring them.

5- Implementation of the proposed program of folk dance on refugee women in different countries, because it has achieved a lot of positive results in this research.

\section{References:}

1- Abd El-Aziz Fahmy El-Nouhy. General Practice in Social Service - The Problem Solving Process within an Ecological Contextual Framework -, Series Towards Advanced Social Care, Faculty of Social Work, Helwan University, Cairo, 2001.

2- Abd El-Hadi Bin Mohamad Al-Qahtani. Psychological Stress and its Relationship with Optimism, Pessimism and Some School Variables for a Sample of Secondary Stage Students in Al-Khobar Governorate in the Eastern Province of the Kingdom of Saudi Arabia, Unpublished Master Thesis, Faculty of Arts, University of Bahrain, 2013.

3- Ahmed Hassan Gomaa. Motion in the Art of Ballet, The Egyptian General Book Organization, Cairo, 2005.

4- - Alia Shams El-Din. The Impact of a Suggested Program for Typo Training on Improving Some Fitness elements, Physiological Variables, and Performance Level in Modern Dancing, Unpublished Master Thesis, Faculty of Physical Education for Girls, Zagazig University, 2004.

5- Amani Mahmoud Ali. The effectiveness of a sports program on the level of the serotonin hormone to reduce psychological stress and to improve the quality of life for women, unpublished Doctoral Thesis, Faculty of Physical Education for Girls, Alexandria University, 2018.

6- Ameri M., Ghazalian F., Shakeri N., and Akhoond M. R.. Effect of Exercise with Mental Stress on Cortisol and Alpha-Amylase Changes in Young Men. Middle East J Rehabil Health Stud. Published online 2019 October 23.

7- - Bahaa El-Din Ibrahim Salama. Biochemical properties of sports physiology, Dar AlFikr Al-Arabi, Cairo, 2008.

8- Berenbaum H., and Fujita F.. Schizophrenia and personality: exploring the boundaries and connections between vulnerabilities and outcome. Journal of Abnormal Psychology. (1994). 103, 148-158.

9- Cooper, CL, and Marshall. Understanding Executives Stress. London Marmillan Press. Cornell, M, 1979. 
10- - Eglal Muhammad Ibrahim, Nadia Muhammad Darwish. Modern Innovative Dance, 1994.

11-El-Sayed Derbala. The effect of show exercises on some physiological and morphological variables in students of the Faculty of Physical Education in Tanta, Journal of Theories and Applications, Alexandria University, No. 30, 1999.

12- Faeq Shaaban. Pages from the history of the art of dance in the world, Dar Aladdin Publishing, Distribution and Translation House, Damascus, 1993.

13- Fatma Salim El-Azab. Scientific Foundations of folk dance expression, Port Said Printing House, Alexandria, 1990.

14- "Folk dance." Merriam-Webster.com Dictionary, Merriam-Webster, https://www.merriam-webster.com/dictionary/folk\%20dance. Accessed 19 Mar. 2020.

15- Ghosun Fadel Hadi. Some indicators of obesity (body mass and fat mass) and their relationship to the oxygen potential of students of the College of Physical Education and Sports Science. Al-Mustansiriya University, Maysan Journal of Physical Education Sciences, 2016.

16- Hassan Mustafa Abdel-Motti. Life stresses and methods of coping with them, Zahraa AlShorouk Library, Cairo, 2006.

17- Heba Mohamed Gharib. Effectiveness of a counseling program based on sports activities to reduce stress, Unpublished Master Thesis, Institute of Educational Studies, Cairo University, 2010.

18- Helmy Ibraheem, Laila El-Sayed. Physical Education and Recreation for the Handicapped, Arab Thought Center, Cairo, 1998.

19- Hussein Ahmed Heshmat. Abd El-Kafi Abd El-Aziz Ahmed: Biotechnology and Genetic Stimulants in the Sports Field, National Book House, Benghazi, 2010.

20- Khaled Ali Al-Hashemi. Effectiveness of a suggested counseling program to reduce perceived psychological stress among high school students in Kuwait, unpublished Doctoral Thesis, Institute of Educational Studies, Cairo University, 2011.

21-Kopp B., Mattler U., and Rist F. Selective attention and response competition in schizophrenic patients. Psychiatry Research, (1994), 53(2), 129-139.

22- Lazarus, R. S., Cohen, J. B. "Environmental Stress", in Altman, I, Wohlwill, J. (Eds.), Human Behaviour and Environment, New York: Plenum Press.(1977)

23-Lazarus, R. S., and Folkman, S. Stress, Appraisal and Coping. NewYork: Springer. (1984). p. 14

24- Lynn Goldberg, Diane L. Elliott. The Effect of Exercise on Healing, Obeikan Library, Saudi Arabia, 2002.

25- Maram Mohamed Ahmed. A sports counseling program to address the severity of anxiety of some breast cancer patients at the Cancer Center - Mansoura University, Doctoral Thesis, Faculty of Physical Education for Girls, Mansoura University, 2018.

26- Maryam Hanna Tadros. Psychological Stress Associated with SLC6A4 Gene Patterns for Some High Level Sports Players, Unpublished Doctorate Thesis. Faculty of Physical Education for Girls, Alexandria University, 2018.

27- Akandere M. and Demir B.. The Effect of Dance over Depression, Coll. Antropol. 35 (2011) 3: 651-656

28- Mohamad Al-Hujairi. When Dabke Dance become the title of Lebanese identity. Itmoved from Country Theater to television, the Lebanese newspaper, p. 1, 2013

29- Mohamed Al-Saeed Abd El-Gawad. Positive Psychology, Arab and Psychological Sciences Foundation, 2014.

30- Mohamed Hassan Allawi. An Introduction to Sports Psychology, Dar Al-Kitab Publishing, Cairo, 2002. 
31- Mohamad Mohamad Al-Hamami. Mathematics for All - Philosophy and Practice - The Book Center for Publishing, Cairo, 1997.

32- Mosa Fahmy Ibrahim, Adel Ali Hassan. Exercises and Sports Shows, Dar Al-Maarif, Cairo, 1991.

33- Nabila Ahmed Abu Habib: Psychological Stress and Strategies to Confront it and its Relationship to Academic Achievement in the Families of the Martyrs in Gaza Governorates, Unpublished Master Thesis, Faculty of Education, Al-Azhar University, 2010.

34- Nabil Ragheb: Body Language of Expression in the in Art, Trade, and Politics, Dar Gharib for Printing, Publishing and Distribution, Cairo, 1998.

35- Nawal Abd Al-Rahman Al-Amer. The Effectiveness of a Suggested Training Program Based on Meaningful Therapy to Confront Psychological Stress and Reduce Anxiety and Depression in a Sample of High School Students in the Kingdom of Bahrain, Unpublished Doctorate Thesis, Faculty of Education, University of Alexandria, 2018.

36- Nisreen Emran. Dabke is a dance that expresses aggression and persistence, Makkah AlMukarramah newspaper, p. 1.

37- Osama Kamel Rateb. Training of Psychological Skills - Applications in the Sports Field Dar Al-Fikr Al-Arabi, Cairo, 2000.

38-Othman Yakhlef. Health Psychology "Psychological and Behavioral principles of Health", Dar Al Thaqafa, Doha, 2001.

39- Soha Mohamed Fikry, Ola Tawfik Ibrahim. The Skill Performance in Motion Expression and its Relationship with Some Personal Attributes of Students in the Faculty of Physical Education for Girls, Scientific Journal of Research and Studies in Physical Education, Faculty of Physical Education in Port Said, Suez Canal University, Sixth Issue, June 2003.

40- Taylor B., Zimmer C., and Womack S. T.. Strategies to prevent teacher stress and burnout, eric publications ,2005 .

41- "The Dabke-An Arabic Folk Dance". History and Development of Dance/ Brockport. 9 May 2013.

42- Wafaa Mohamad Al-Mahi: Aesthetic Values and Their Relationship with the Level of Skill Performance in motion Expression among Students of the Faculty of Physical Education, Tanta University, The Scientific Journal of Physical Education and Sports, Eighteenth Issue, Faculty of Physical Education for Girls, Alexandria University, 2000.

43- Wafaa Mohamad Darwish. Sports Psychology "Theories and Applications", Al-Wafaa Publishing House, Alexandria, 2014.

44- Wegner M., Koutsandréou F., Müller-Alcazar A., Lautenbach F. and Budde H. Effects of Different Types of Exercise Training on the Cortisol Awakening Response in Children. Front. Endocrinol. (2019) 10:463. 